\title{
Wellness of Undergraduates: Comparisons of Traditional and Nontraditional Students
}

\author{
Jane E. Myers and A. Keith Mobley
}

\begin{abstract}
Wellness scores of 1,249 traditional and 318 nontraditional undergraduate college students revealed low levels of wellness in multiple areas in comparison with non-student adults and within-group differences according to demographic variables. Profiles of wellness for traditional- and nontraditional-age students revealed significant differences on 4 subscales. Nontraditional students of color scored lower than traditional Caucasian students on Total Wellness and several component indices. Implications for student development and counseling programs are discussed.
\end{abstract}

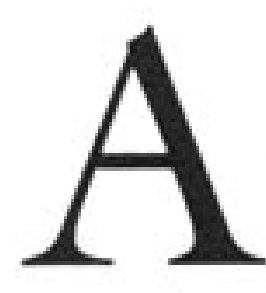

Imost two decades ago, Hettler (1984) and others (e.g., DeStephano \& Harger, 1990) recommended the establishment of campus wellness programs as a means of addressing both the personal and academic needs of students. Evidence from multiple studies support the long-term value of these programs, both as cocurricular and curricular experiences, in such diverse areas as stress management, interpersonal relationship skills, nutrition (Koehler \& Burke, 1996), and career development (Vecchione, 2000), all of which can affect academic success (Brazier, 1998). Although various authors have emphasized the need for campus wellness programs and have discussed strategies for developing such programs, it is noteworthy that few studies of student wellness exist. Furthermore, although much has been written about differing needs of traditional-age (24 years and under) and nontraditional-age (25 years and over) undergraduate students (Kim, 2002; Luzzo, 1999; Morris, Brooks, \& May, 2003), little has been written about the design of campus wellness programs to accommodate the differing needs of these students.

Archer, Probert, and Gage (1987) studied wellness in 3,190 undergraduate college students using global ratings corresponding to Hettler's (1984) hexagonal model of wellness (i.e., physical, emotional, spiritual, occupational, social, and intellectual wellness). Students rated the physical dimension as most important but wanted more information on emotional aspects of wellness. Showalter (1995) conducted a needs assessment of 1,082 college freshmen relative to knowledge and use of campus wellness programs. He found few differences based on ethnicity but reported that women rated wellness factors as more significant than did men. Stock, Willie, and Kraemer (2001), in a needs assessment study of health promotion, also found gender differences in health behaviors among 288 freshmen, with women reporting more preventive health behaviors, except in the area of unprotected sex.

A literature review of the PsycINFO database revealed only one study of wellness that compared traditional-age with nontraditional-age students. Hybertson, Hulme, Smith, and Holton (1992) found that the two groups perceived different factors as beneficial or detrimental to their personal wellness. Nontraditional-age students

Jane E. Myers and A. Keith Mobley, Department of Counseling and Educational Development, The University of North Carolina at Greensboro. A. Keith Mobley is also in private practice. Correspondence concerning this article should be addressed to Jane E. Myers, Department of Counseling and Educational Development, The University of North Carolina at Greensboro, PO Box 26170, Greensboro, NC 27402-61 70 (e-mail: jemyers@uncg.edu). 
most frequently chose the beneficial factor of "balancing my personal needs with the demands from others" and traditional-age students most frequently selected "knowing who I am, having good self-awareness." The most frequently chosen detrimental factor for nontraditional-age students was "feeling overwhelmed or conflicted about fulfilling all my role responsibilities"; for the traditional-age students, it was "worrying." Presumably, these factors may affect retention in the college setting for students of all ages, including ethnic minority as well as Caucasian students (Allen, 1994; Bagayoko \& Kelley, 1994; Reyes, 1997; Walters, 1996; Wilson, Mason, \& Ewing, 1997).

Although the studies cited here are helpful in establishing a variety of parameters of wellness among college students, additional research is needed to provide a foundation for holistic campus wellness programs that specifically address the differential needs of traditional-and nontraditional-age students. Research based in holistic models that provide multidimensional wellness assessment can contribute to further understanding the needs of undergraduate students and to strategies for developing campus wellness and health promotion programs. $\mathrm{Ar}$ cher and Cooper (1999) identified college counselors as the typical campus "change agents" for promotion of new and better student development programs; hence, models grounded in counseling theory, such as the Wheel of Wellness (Myers, Sweeney, \& Witmer, 2000; Sweeney \& Witmer, 1991) and the Indivisible Self (IS-Wel), an evidence-based model of wellness (Myers \& Sweeney, in press), may be most useful as a basis for further study of college student populations. Thus, the present study was undertaken to examine and compare the wellness of traditional- and nontraditional-age undergraduate students. The research questions posed were the following: How does the wellness of traditional and nontraditional undergraduate students compare with one another and with that of non-student adults? Are there within-group differences in wellness of undergraduate students based on age, gender, or ethnicity?

\section{Method}

The methodology for this study involved the analysis of data from an existing and unexamined database developed over a 5-year period using the Five Factor Wel (5FWel; Myers \& Sweeney, 1999), an instrument that was developed from the Wellness Evaluation of Lifestyle (WEL; Myers, Sweeney, \& Witmer, 1996) and that has improved psychometric properties over the WEL (Myers \& Sweeney, in press). All participants completed the $5 \mathrm{~F}$-Wel voluntarily in undergraduate and graduate classes, through community workshops, and through research and service projects in the community. The institutions where students completed the $5 \mathrm{~F}$-Wel included both small and intermediate-size, 2- and 4-year colleges and universities in North Carolina, Louisiana, Arkansas, Ohio, Minnesota, and Florida.

\section{Participants:The 5F-Wel Database}

A total of 1,567 undergraduate students included in the $5 \mathrm{~F}$-Wel database were examined in this study. Most (83\%) were traditional college age (i.e., age 24 years or under), and almost $14 \%$ were nontraditional, age 25 years and over. More than half $(57 \%)$ of the students were female, and $42 \%$ were male (due to missing data 
the numbers do not add to $100 \%$ ). Approximately $61 \%$ of the undergraduates were Caucasian, 15.5\% were African American, and 19\% reported other ethnic backgrounds, including Hispanic, Asian American, and Native American. Most (86\%) were single, but $8.4 \%$ were married and $3.4 \%$ were separated, widowed, or divorced.

\section{The $5 \mathrm{~F}-\mathrm{Wel}$}

The 5F-Wel (Myers \& Sweeney, 1999) was developed to assess the factors of wellness identified in the IS-Wel (Myers \& Sweeney, in press), an evidence-based model of wellness. This model emerged from factor-analytic studies of a large database that was developed on the basis of the Wheel of Wellness model (Myers et al., 2000), which is grounded in Adlerian theory and cross-disciplinary research on health, quality of life, and longevity. The IS-Wel model emphasizes the indivisibility of the self, while simultaneously identifying 5 interrelated secondorder factors of wellness and 17 third-order factors. The 17 discrete third-order factors listed in Table 1 are grouped according to the 5 second-order factors (Social Self, Essential Self, Creative Self, Physical Self, and Coping Self).

The $5 \mathrm{~F}$-Wel includes 73 items that are behavioral and attitudinal statements, such as "I believe in the existence of a power greater than myself" and "I am an active person." Responses are made using a 5-point Likert-type scale, and scores are simple sums of items on each scale. A linear transformation places all scales on a common metric with a possible range of 25 to 100 .

Exploratory and confirmatory factor analyses supported 1 first-order, 5 secondorder, and 17 discrete third-order factors in the IS-Wel model (Hattie, Myers, \& Sweeney, in press). Reliabilities were reported as .92 for the single higher order or Total Wellness factor, .58 to .73 for the 5 second-order factors, and .60 to .94 for the third-order factors. In the present study, the alpha was .89 for Total Wellness, the second-order factor alphas ranged from .77 to .87 , and the third-order factor alphas ranged from .60 to .83 .

\section{Statistical Analyses}

Descriptive statistics for all 5F-Wel scales were computed for traditional-and nontraditional-age undergraduate students and a norm group of non-student adults. A series of $t$ tests were conducted to compare the undergraduate students with the 702 non-student adults (Myers, Mobley, \& Booth, 2003), and Levene's test was used to assess the homogeneity of variance between the two sets of scores. Due to the large number of comparisons, the family-wise error rate was adjusted using Bonferroni's $t$ and the alpha level set at .003 to determine statistical significance. Cohen's $d$ was used to examine the effect sizes of the significant differences. Effect sizes are useful indices that measure the magnitude of an effect independent of sample size and are interpreted as being small (.20), medium (.50), or large (.80 or higher). This statistic was calculated using the pooled standard deviation to control for differences in the degrees of freedom of the different subgroups used in the analyses.

Multivariate analysis of variance (MANOVA) was used to examine the relationships between the selected dichotomous demographic variables 


\section{TABLE 1}

Mean Scores for Nontraditional- and Traditional-Age Undergraduates and $t$ Tests for Comparisons of Means of Undergraduates and Non-Student Adults With Levene's Test and Bonferroni Correction $(p<.003)$

\begin{tabular}{|c|c|c|c|c|c|c|c|c|c|c|c|}
\hline \multirow[b]{3}{*}{ 5F-Wel Scale } & \multicolumn{6}{|c|}{ Undergraduate Students } & & & \multirow[b]{3}{*}{$t$} & \multirow[b]{3}{*}{$p$} & \multirow[b]{3}{*}{$d$} \\
\hline & \multicolumn{2}{|c|}{$\begin{array}{c}\text { Nontraditional } \\
\quad(n=318)\end{array}$} & \multicolumn{2}{|c|}{$\begin{array}{l}\text { Traditional } \\
(n=1,249)\end{array}$} & \multicolumn{2}{|c|}{$\begin{array}{c}\text { Total } \\
(n=1,567)\end{array}$} & \multicolumn{2}{|c|}{$\begin{array}{c}\text { Non-Students } \\
(n=702)\end{array}$} & & & \\
\hline & $M$ & $S D$ & $M$ & $S D$ & $M$ & $S D$ & $M$ & $S D$ & & & \\
\hline Social Self & 84.93 & 11.5 & 83.82 & 11.7 & 84.20 & 11.0 & 87.78 & 11.7 & -7.175 & $<.001$ & -.20 \\
\hline Friendship & 82.73 & 13.4 & 74.85 & 13.0 & 83.64 & 12.0 & 86.19 & 12.0 & -4.343 & $<.001$ & -.21 \\
\hline Love & 86.21 & 13.2 & 84.45 & 12.7 & 84.74 & 12.8 & 90.04 & 13.0 & -9.380 & $<.001$ & -.41 \\
\hline Essential Self & 80.74 & 11.0 & 79.16 & 10.8 & 79.41 & 10.9 & 81.09 & 11.1 & -3.406 & .001 & .15 \\
\hline Spirituality & 80.74 & 15.8 & 77.25 & 16.9 & 77.25 & 16.9 & 78.09 & 18.8 & -0.302 & .763 & \\
\hline Self-Care & 82.42 & 14.4 & 81.51 & 15.6 & 81.65 & 15.4 & 87.70 & 13.9 & -9.153 & $<.001$ & -.41 \\
\hline Gender Identity & 81.08 & 12.9 & 81.07 & 12.5 & 81.08 & 12.6 & 82.11 & 11.8 & -2.133 & .033 & \\
\hline Cultural Identity & 78.03 & 14.6 & 76.64 & 14.7 & 76.86 & 14.7 & 77.25 & 14.4 & -0.429 & .668 & \\
\hline Creative Self & 78.62 & 10.0 & 78.18 & 9.1 & 78.25 & 9.2 & 80.15 & 9.7 & -4.512 & $<.001$ & -.20 \\
\hline Thinking & 78.87 & 11.9 & 76.89 & 11.6 & 77.19 & 11.7 & 80.68 & 10.5 & -7.043 & $<.001$ & -.32 \\
\hline Emotions & 79.93 & 11.8 & 78.67 & 12.1 & 78.86 & 12.1 & 81.16 & 12.1 & -4.343 & $<.001$ & -.19 \\
\hline Self-Control & 79.70 & 11.9 & 80.62 & 11.4 & 80.48 & 11.5 & 80.65 & 11.6 & -0.400 & .689 & \\
\hline Positive Humor & 78.51 & 13.1 & 80.11 & 12.2 & 79.86 & 12.3 & 82.53 & 13.1 & -4.724 & $<.001$ & -.21 \\
\hline Work & 76.11 & 13.7 & 74.65 & 12.8 & 74.85 & 13.0 & 76.68 & 13.4 & -3.241 & .001 & -.14 \\
\hline Physical Self & 71.49 & 16.5 & 74.01 & 14.6 & 73.61 & 14.9 & 70.40 & 30.0 & 2.612 & .009 & \\
\hline Nutrition & 70.16 & 19.3 & 69.49 & 18.4 & 69.58 & 15.5 & 69.21 & 39.5 & 1.765 & .078 & \\
\hline Exercise & 72.79 & 16.6 & 78.52 & 14.8 & 77.61 & 15.2 & 75.66 & 16.0 & 2.938 & .003 & .13 \\
\hline Coping Self & 70.57 & 10.5 & 70.65 & 8.6 & 70.64 & 9.0 & 69.89 & 17.9 & 1.139 & .255 & \\
\hline Realistic Beliefs & 54.10 & 15.2 & 48.20 & 13.3 & 49.10 & 13.7 & 57.45 & 13.5 & -12.92 & $<.001$ & -.61 \\
\hline Stress Management & 73.95 & 16.1 & 74.75 & 15.4 & 74.61 & 15.5 & 75.29 & 14.2 & -0.898 & .369 & \\
\hline Sense of Worth & 82.40 & 13.7 & 81.37 & 13.2 & 81.54 & 13.3 & 79.63 & 45.1 & 2.705 & .007 & \\
\hline Leisure & 74.23 & 15.3 & 79.53 & 12.7 & 78.69 & 13.3 & 75.49 & 13.4 & 3.190 & .001 & .24 \\
\hline Total Wellness & 76.68 & 9.3 & 76.35 & 8.0 & 76.40 & 8.3 & 76.57 & 10.5 & -1.474 & .141 & \\
\hline
\end{tabular}

Note. $5 \mathrm{~F}-\mathrm{Wel}$ scale $=$ Five Factor Wel scale. 
(i.e., gender, ethnicity, age). Interaction effects were evaluated using a twoway analysis of variance among age and both gender and ethnicity and a three-way analysis using the same variables; Wilks's lambda was used to evaluate significance.

\section{Results}

Descriptive statistics for nontraditional-and traditional-age students (the total sample of 1,567 undergraduate students) and for the 702 non-student adults are provided in Table 1 . Both nontraditional and traditional students scored highest on the Social Self factor $(M=84.93, S D=11.5$ and $M=84.14, S D=11.0$, respectively). Both nontraditional and traditional students also scored lowest on Coping Self $(M=70.57, S D=10.5$ and $M=70.65, S D=8.6$, respectively). The most variability in scores occurred for both groups for the Physical Self factor ( $S D s=16.5$ for nontraditional students and 14.6 for traditional students).

As shown in Table 1,13 of the $23 t$ tests between the 1,567 students and the norm group of non-student adults were significant. Undergraduates scored lower on 11 comparisons. Although most of the effect sizes were small, 2 were medium (Love and Self-Care, $d=.41$ for both), and 1 was moderately large (Realistic Beliefs, $d=.61$ ). Undergraduates scored higher than the adult nonstudent sample on Exercise and Leisure, but both effect sizes were small $(d=.13$, .24). There were no differences in Total Wellness between the groups.

As shown in Table 2, MANOVAs computed to examine possible within-group differences based on age, gender, and ethnicity revealed significant main effects for all three variables. Subgroups having the highest scores are noted for each significant difference. Nontraditional-age students scored higher on Spirituality and Realistic Beliefs, and traditional-age students scored higher on Exercise and Leisure. Female students scored higher than male students on Love and Essential Self. Male students scored higher than female students on eight factors: Physical Self, including Nutrition and Exercise; Positive Humor; and the second-order Coping Self factor plus three related third-order factors of Stress Management, Sense of Worth, and Leisure. There were no significant interaction effects of age by gender.

Due to the relatively small number of students of color, the cell sizes were too small to permit valid analyses except by grouping the data into two broad ethnic categories, Caucasian students and students of color. Caucasian students scored higher than students of color on six factors (Social Self, Friendship, Self-Control, Physical Self, Exercise, and Leisure), and students of color scored higher than Caucasian students on two (Cultural Identity and Realistic Beliefs).

There were numerous interaction effects when age and ethnicity were examined together. In each case, nontraditional students of color scored lower than traditional-age Caucasian students. These differences were found for the higher order Total Wellness factor; the second-order factors of Essential Self, Creative Self, and Coping Self; and several of the third-order factors (Self-Care, Thinking, Nutrition, Stress Management, and Sense of Worth). 
TABLE 2

Main Effects and Interactions for Within-Group Multivariate Analyses of Variance by Age, Gender, and Ethnicity

\begin{tabular}{|c|c|c|c|c|c|c|c|c|}
\hline \multirow[b]{3}{*}{ 5F-Wel Scale } & \multicolumn{6}{|c|}{ Main Effects } & \multirow{2}{*}{\multicolumn{2}{|c|}{$\begin{array}{c}\text { Interaction } \\
\text { Effects }\end{array}$}} \\
\hline & \multicolumn{2}{|c|}{ Age $^{a}$} & \multicolumn{2}{|c|}{ Gender ${ }^{b}$} & \multicolumn{2}{|c|}{ Ethnicity ${ }^{b}$} & & \\
\hline & $F$ & $p$ & $F$ & $p$ & $F$ & $p$ & $F$ & $p$ \\
\hline Social Self & 0.21 & .649 & 7.29 & .007 & 10.31 & $<.001^{9}$ & 5.84 & .016 \\
\hline Friendship & 1.63 & .201 & 2.54 & .111 & 8.89 & $<.003^{9}$ & 3.71 & .054 \\
\hline Love & 3.73 & .054 & 10.69 & $<.001^{\circ}$ & 7.52 & .006 & 5.67 & .017 \\
\hline Essential Self & 4.20 & .041 & 10.57 & $<.001^{\circ}$ & 2.15 & .143 & 18.73 & $<.001^{c . g}$ \\
\hline Spirituality & 8.59 & $<.003^{\circ}$ & 6.16 & .013 & 5.60 & .018 & 24.48 & $<.001^{c .9}$ \\
\hline Self-Care & 0.68 & .410 & 5.95 & .015 & 0.46 & .497 & 0.42 & .516 \\
\hline Gender Identity & 0.00 & .998 & 2.13 & .145 & 8.08 & .005 & 7.36 & .007 \\
\hline Cultural Identity & 1.76 & .185 & 7.8 & .005 & 13.91 & $<.001^{\mathrm{h}}$ & 14.44 & $<.001^{c, g}$ \\
\hline Self & 0.42 & .515 & 0.27 & .602 & 6.92 & .009 & 12.77 & $<.001^{c . g}$ \\
\hline Think & 5.74 & .017 & 0.00 & .962 & 4.65 & .031 & 10.92 & $<.001^{c, g}$ \\
\hline Emotions & 2.20 & .138 & 0.50 & .482 & 0.43 & .513 & 4.61 & .032 \\
\hline Self-Control & 1.28 & .259 & 0.21 & .644 & 11.93 & $<.001^{9}$ & 6.41 & .011 \\
\hline Positive Humor & 3.32 & .068 & 10.44 & $<.001^{\prime}$ & 5.01 & .025 & 0.75 & .386 \\
\hline Work & 2.64 & .105 & 0.60 & .438 & 2.69 & .101 & 22.43 & $<.001^{c, 9}$ \\
\hline Physical Self & 5.65 & .018 & 36.90 & $<.001^{\prime}$ & 15.32 & $<.001^{\circ}$ & 8.04 & .005 \\
\hline Nutrition & 0.26 & .612 & 15.02 & $<.001^{\prime}$ & 5.67 & .017 & 10.62 & $<.001^{c, g}$ \\
\hline Exercise & 28.40 & $<.001^{\mathrm{d}}$ & 50.96 & $<.001^{\prime}$ & 23.16 & $<.001^{9}$ & 2.45 & .118 \\
\hline Coping Self & 0.02 & .890 & 40.93 & $<.001^{1}$ & 0.08 & .785 & 12.34 & $<.001^{c, g}$ \\
\hline Realistic Beliefs & 37.44 & $<.001^{\circ}$ & 0.16 & .682 & 20.78 & $<.001^{h}$ & 0.11 & .744 \\
\hline Stress & & & & & & & & \\
\hline Management & 0.51 & .474 & 39.28 & $<.001^{\prime}$ & 0.22 & .642 & 12.54 & $<.001^{c, g}$ \\
\hline Sense of Worth & 1.21 & .271 & 13.13 & $<.001^{\prime}$ & 3.27 & .071 & 13.98 & $<.001^{c, g}$ \\
\hline Leisure & 31.81 & $<.001^{d}$ & 35.72 & $<.001^{t}$ & 17.36 & $<.001^{9}$ & 3.76 & .052 \\
\hline Total Wellness & 0.33 & .568 & 3.45 & .064 & 2.14 & .144 & 19.39 & $<.001^{c .9}$ \\
\hline
\end{tabular}

Note. $5 \mathrm{~F}-\mathrm{Wel}$ scale $=$ Five Factor Wel scale.

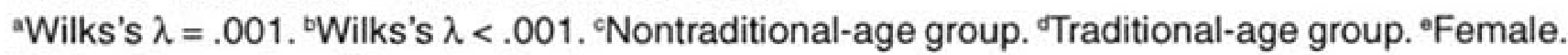
'Male. ${ }^{\circ}$ Caucasian. " $\mathrm{P}$ eople of color.

\section{Discussion}

Wellness of undergraduates on 1 higher order, 5 second-order, and 17 third-order factors of the $5 \mathrm{~F}$-Wel were examined using an existing database of 1,249 traditionalage and 318 nontraditional-age students. Between-group comparisons of all undergraduates with 702 non-student adults revealed that undergraduates scored lower on 13 of the 23 factors, including 3 of the second-order factors (Social, Essential, and Creative Self). Undergraduates scored higher on Exercise and Leisure. Within-group comparisons resulted in numerous statistically significant differences based on age (4 differences), gender (10 differences), and ethnicity ( 8 differences). Interaction effects of age by ethnicity revealed 11 differences; in each case, nontraditional-age Caucasian students scored higher than nontraditional-age students of color.

The $5 \mathrm{~F}$-Wel sample of undergraduates included $57 \%$ women, slightly less than the national average for gender distributions of undergraduate students. The National 
Center for Education Statistics (2001) reported 69\% female undergraduate enrollment in 1999. Luzzo (1999) reported that between one third and one half of college students are nontraditional age. In contrast, the $5 \mathrm{~F}$-Wel sample included only $14 \%$ in this group. Thus the $5 \mathrm{~F}-\mathrm{Wel}$ sample is not truly representative of the national distribution of undergraduate college students, and the results should be interpreted with caution relative to students in any particular geographic region, gender, ethnicity, or age group. Furthermore, it should be noted that only significant differences with medium-to-large effect sizes are meaningful in a practical sense.

An examination of the between-groups comparisons demonstrates that traditional-age undergraduate students, as a whole, are at risk for lower wellness than non-student adults, most notably in the area of Realistic Beliefs, for which the effect size of the differences was large. The Realistic Beliefs scale was derived from an analysis of Ellis's concepts of irrational beliefs (as cited in Myers et al., 2000). The $5 \mathrm{~F}$-Wel items in this scale include statements such as "It is important for me to be liked or loved by almost everyone I meet." Low scores on this scale reflect perfectionist tendencies and a need to be perceived by others as likable and competent. Although scores on this scale tend to be the lowest of all $5 \mathrm{~F}-\mathrm{Wel}$ scales across populations (Hattie et al., in press), the large effect sizes suggest that undergraduates tend to have particularly high standards and, at the same time, concerns that they are not living up to those standards.

The finding that undergraduates scored lower than non-student adults on Intellectual Stimulation, Problem Solving, and Creativity could reflect developmental challenges related to college experiences. The $5 \mathrm{~F}$-Wel scale includes an orientation toward solving problems, a feeling that one is adept at problem-solving processes, and an appreciation for the challenges and predicaments of life. The fact that nontraditional-age undergraduate students scored higher on this scale than did traditionalage undergraduates supports a possible developmental component in the problemsolving concept or, perhaps, the security that comes from successfully resolving life challenges and a consequent positive view of oneself as an effective problem solver.

The lower scores for undergraduates in comparison with non-student adults on Self-Care were not surprising in light of the literature on college student wellness (and non-wellness) behaviors (e.g., Barnes, 1998; DeStephano \& Harger, 1990; Showalter, 1995). Items on the Self-Care scale refer to safety behaviors (i.e., wearing seat belts regularly), preventive health behaviors (e.g., preventive medical and dental screenings), and avoidance of negative health practices (e.g., use of tobacco and alcohol). These scores provide strong support for continued attention to broadbased preventive and wellness interventions for all undergraduate populations.

It is noteworthy that traditional-age undergraduates scored lower on Social Self and both Friendship and Love compared with non-student adults. The 5-Wel Friendship items include statements such as "I have friends who would do most anything for me if I were in need" and "I initiate and maintain relationships that are satisfying to me." It appears that traditional-age undergraduate students are challenged relative to the establishment of friendships, as reflected in lower scores on this scale. Further studies in which individual items are examined could be helpful in explaining the dynamics of lower wellness in the friendship area. Similarly, items on the Love scale include statements such as "I have at least one intimate relationship that is secure 
and lasting." Low scores here reflect a lack of success in forming and maintaining intimate relationships.

Although effect sizes were small except for Love, taken as a whole, these results suggest that relationship issues may be more of a concern for students than they are for nonstudents. This conclusion is supported by the within-group analyses. Myers et al. (2000) provided a brief review of studies examining the critical role of social support as a factor affecting positive mental health over the life span. Developmental theorists (e.g., Erikson, 1963) have noted that intimacy is a central challenge primarily for young adults. The dynamics of relationship issues for undergraduates merit further exploration based on these results, as does the development of support programs for all students regardless of age. Within-group analyses did reveal differences, suggesting that men and students of color are most at risk for lower social wellness and thus most in need of support programs.

The only areas in which the undergraduate students scored higher than adult nonstudents were Exercise and Leisure. These findings were not surprising. The ease of accessibility to campus recreation facilities may be a factor affecting this finding, as well as the greater leisure time available to undergraduates in comparison with the other groups. Myers et al. (2000) noted the interactive effects of the wellness components, such that change in one area contributes to and causes change in other areas. Thus, positive exercise habits can contribute to greater wellness in other areas and lead to overall or total wellness. Encouragement of exercise and satisfying leisure for all undergraduates can only have a positive overall effect. The higher scores for physical wellness (exercise) as well as greater leisure wellness could be related to greater immersion in campus life and freedom to take advantage of campus facilities for meals, exercise, and other activities. Nontraditional-age students typically have more responsibilities for family and work; hence, leisure and exercise, as well as regular meals, may be less available options for them.

A variety of differences were noted when comparisons were made within the sample of undergraduates. An examination of patterns suggests that the male undergraduates reported higher wellness than did the female undergraduates in a variety of areas. This finding is contrary to existing research by Showalter (1995), as well as by Stock et al. (2001), that suggested that female undergraduates were both more knowledgeable than male undergraduates about wellness behaviors and more inclined toward prevention. Further studies of gender differences in wellness are warranted to verify, explain, or refute the current findings.

The finding that students of color experience greater wellness in terms of their Cultural Identity was not surprising; ethnic minority individuals are often more aware of culture than are their Caucasian peers. The finding of higher Realistic Beliefs in this group was not consistent with prior studies, notably the Hattie et al. (in press) study, in which students of color scored higher on Sense of Worth but not on other areas of wellness. Further studies of these variables across ethnic groups would provide a stronger basis for explanation as well as program development to meet the needs of students of color in higher education.

\section{Implications}

The current findings suggest that undergraduate college students experience lower wellness than non-student adults and that traditional- and nontraditional- 
age college students only differ on a few aspects of wellness. Counselors and student development professionals may find it useful to assess students for overall wellness as well as for specific components of wellness in order to target interventions matched to the needs of various students. Factors to consider include demographic indices (i.e., age, gender, ethnicity) as well as student status (i.e., traditional vs. nontraditional).

College student success courses and campus wellness programs are important means to promote greater wellness during the college years. In addition, individual and group counseling targeted at areas of known concern, such as realistic beliefs, could help to enhance the well-being of students during their college years. Wellness choices have holistic and lifelong effects (Myers et al., 2000); hence, a focus on the development of wellness behaviors during college sets the stage for healthier functioning across the life span. Perhaps additional courses on wellness can be added as electives so that both traditional and nontraditional students who do not need to enroll in success courses may still experience the benefits such courses might offer.

The current findings provide strong support for continued attention to broadbased preventive and wellness interventions on college campuses and to the development of programs specific to the needs of both traditional and nontraditional students, especially those who are ethnic minorities. The use of holistic wellness assessment instruments, such as the $5 \mathrm{~F}$-Wel, combined with additional assessments targeted at specific areas of wellness can serve as a basis for program development in the future. In addition, the development of local institutional norms for wellness can help program planners evaluate the success of wellness interventions over time and provide a knowledge base for future research on college student wellness.

\section{References}

Allen, B. A. (1994). The student in higher education: Nontraditional student retention. The Community Services Catalyst, 33. Retrieved September 18, 2003, from http://scholar.lib.vt.edu/ ejournals/CATALYST/V23N3/allen.html

Archer, J., Jr., \& Cooper, S. (1999). An initiator-catalyst approach to college counseling outreach. Journal of College Counseling, 2, 76-88.

Archer, J., Probert, B. S., \& Gage, L. (1987). College students' attitudes toward wellness. Journal of College Student Personnel, 28, 311-317.

Bagayoko, D., \& Kelley, E. (1994). The dynamics of student retention: A review and a prescription. Education, 115, 31-40.

Barnes, J. T. (1998). The impact of an undergraduate health education class on students' wellness knowledge, attitude and behavior. Dissertation Abstracts International, 58(7-A), 2553.

Brazier, A. A. (1998). Nontraditional students in nontraditional graduate programs in education: Coping with the conflicts between family and career responsibilities and the institutional demands of higher education. Dissertation Abstracts International, 59(2-A), 0393.

DeStephano, T. J., \& Harger, B. (1990). Promoting the wellness lifestyle on a college campus. Journal of College Student Development, 31, 461-462.

Erikson, E. (1963). Childhood and society. New York: Norton.

Hattie, J. A., Myers, J. E., \& Sweeney, T. J. (in press). A multidisciplinary model of wellness: The development of the Wellness Evaluation of Lifestyle. Journal of Counseling \& Development.

Hettler, W. (1984). Wellness: Encouraging a lifetime pursuit of excellence. Health Values: Achieving High Level Wellness, 8, 13-17.

Hybertson, D., Hulme, E., Smith, W., \& Holton, M. A. (1992). Wellness in non-traditional age students. Journal of College Student Development, 33, 50-55. 
Kim, K. (2002). ERIC Review: Exploring the meaning of 'nontraditional' at the community college. Community College Review, 30, 1-6.

Koehler, G., \& Burke, A. (1996). Transforming the treadmill into a staircase: Preparing non-traditional first-generation college attenders for success. (ERIC Document reproduction Service No. ED414959)

Luzzo, D. A. (1999). Identifying the career decision-making needs of nontraditional college students. Journal of Counseling \& Development, 77, 135-140.

Morris, E. A., Brooks, P. R., \& May, J. L. (2003). The relationship between achievement goal orientation and coping style: Traditional vs. nontraditional college students. College Student Journal, 37, 3-6.

Myers, J. E., Mobley, K. A., \& Booth, C. (2003). Wellness of counseling students: Practicing what we preach. Counselor Education and Supervision, 42, 264-274.

Myers, J. E., \& Sweeney, T .J. (1999). The Five Factor Wel. Greensboro, NC: Authors.

Myers, J. E., \& Sweeney, T. J. (in press). The Indivisible Self: An evidence-based model of wellness. Journal of Individual Psychology.

Myers, J. E., Sweeney, T. J., \& Witmer, J. M. (1996). The Wellness Evaluation of Lifestyle. Palo Alto, CA: MindGarden.

Myers, J. E., Sweeney, T. J., \& Witmer, J. M. (2000). The Wheel of Wellness counseling for wellness: A holistic model for treatment planning. Journal of Counseling \& Development, 78, 251-266.

National Center for Education Statistics. (2001). Digest of education statistics. Retrieved September 16, 2003, from http://nces.ed.gov/pubs2000/Digest99/d99t186.html

Reyes, N. (1997). Holding on to what they've got. Black Issues in Higher Education, 20, 36-41.

Showalter, M. K. (1995). An assessment of student wellness needs and perceptions as compared with the wellness perceptions of student affairs professionals. Dissertation Abstracts International, 55(7-A), 1832.

Stock, C., Willie, L., \& Kraemer, A. (2001). Gender-specific health behaviors of German university students predict the interest in campus health promotion. Health Promotion International, 16, 145-154.

Sweeney, T. J., \& Witmer, J. M. (1991). Beyond social interest: Striving toward optimum health and wellness. Individual Psychology, 47, 527-540.

Vecchione, T. P. (2000). An examination of the relationship between career development and holistic wellness among college students. Dissertation Abstracts International, 60(7-A), 2390.

Walters, E. (1996). Embracing the spirit of multiculturalism in higher education as a means of Black and Hispanic student retention. Equity \& Excellence in Education, 29(3), 43-48.

Wilson, S. B., Mason, T. W., \& Ewing, J. M. (1997). Evaluating the impact of receiving university-based counseling services on student retention. Journal of Counseling Psychology, $44,316-321$. 